\title{
Production of biosurfactant from Candida cruzi isolated from produce water oil fields in Basrah for microbial enhance oil recovery
}

\author{
Wijdan H. Al-Tamimi, Ahmed A. Burghal, Najwa M.J.A. Abu-Mejdad \\ Biology Department, College of Science, Basrah University, Basrah, Iraq \\ Corresponding Author: E-mail: wijdanhussien@gmail.com
}

\section{$\underline{\text { Abstract }}$}

The produced water of Nahran Omar oil fields used for isolated the biosurfactant produce Candida cruzi which enhanced by using carbon and nitrogen sources, the biosurfactant production was followed by measuring the oil spreading, emulsification activity, oil collapse and cleaning oil contaminated vessels. The crud biosurfactant was able to spreading the oil (24) mm with (8\%) emulsification activity and oil collapse of $(++)$ the result of cleaning oil contaminated vessels revealed the recovered of oil from the wells of vessels. Under optimization of carbon and nitrogen sources the results revealed that the largest oil displacement was (9) mm with dextrin the maximum emulsification power was ( $92.8 \%$ and $92.5 \%$ ) for lactose and fructose respectively, these results demonstrated the high potential of emulsifiers produced by $C$. cruzi that can play an important role in application in enhance oil recovery.

\section{Introduction}

Microorganisms are use a wide range of organic compounds as a source of carbon and energy for their growth produce a variety of substances are known as biosurfactants. They used these substances when the carbon source is in an insoluble form like a hydrocarbon to make possible their diffusion into the cell [1]. Many microorganisms such as bacteria, yeasts and filamentous fungi are produce the biosurfactants $[2,3]$. The most commonly isolated biosurfactants are glycolibids which classified as rhamnolipid produce by the genus of pseudomonas [4] surfactin and iturin released by Bacillus subtilis strains [5].

Relatively fewer fungi are known to produce biosurfactants. Candida bombicola [6] and Candida lipolytica [7] are among the most commonly studied yeast for the production of sophorolipids [8] also Candida albicans [9], Trichosporonashii [10] (and Aspergillus ustus [11].

Because of the biosurfactants gained several advantages such as low toxicity, better environmental acceptability, high biodegradability and better functionality under extreme conditions $[12,13,14]$ So 
they considered as one of the best alternative of chemically synthesized surfactant in different application $[15,16]$.

Currently the biosurfactants are widely used in petroleum industry, they used in oil spills control, bioremediation of soil and water, removal of oil residue from storage tanks, microbial enhanced oil recovery $[17,18]$. as well as facilitate transportation of heavy crude oil by pipeline [19].

The present research aimed to study the potential of Candida cruzi isolated from produced water of Nahran Omar oil fields in Iraq for biosurfactant production and optimization of cultural conditions to get a high yield of biosurfactant as initiative steps in order to applicants in oil industry.

\section{Material and methods}

\section{$\underline{\text { Sample collection }}$}

Samples of produce water was obtained from the separator tanks of Nahran Omar oil fields, which located in the north of Basrah, oil reservoirs are located at a depth of $\sim(2000-3000) \mathrm{m}$ below ground and the in situ temperature $\sim(50-60){ }^{\circ} \mathrm{C}$ the samples collected in sterile glass bottles and transport immediately to the laboratory for analysis.

\section{Isolation and identification of Candida}

The yeast was isolated by spreading of $0.5 \mathrm{ml}$ of produced water on sterile CSB medium plate [20], incubated at $30^{\circ} \mathrm{C}$ for 7 days. The obtained culture were purified by streaking on Potato Dextrose Agar (PDA). For identification of Candida species using Hicrome Candida Differential Agar (Hi Media Laboratories Pvt. Ltd., India according to manufacturer instructions.

\section{Culture condition and biosurfactant production}

The isolate was activated by aseptically transferred one agar plugs $\left(1 \mathrm{~cm}^{2}\right)$ of the $24 \mathrm{hr}$. pure cultures to nutrient broth at $30^{\circ} \mathrm{C}$ and $120 \mathrm{rpm}$ in a shaker incubator for 5-7 days before using it as inoculums for biosurfactant production in mineral salts medium MSM.

The production medium MSM contained $\left(\mathrm{g} \mathrm{L}^{-1}\right)$ : Sucrose 40; Yeast extract 18.8; Sodium acetate 0.5; Sodium benzoate 0.1; $\mathrm{MgSO}_{4} .7 \mathrm{H}_{2} \mathrm{O} 0.5 ;\left(\mathrm{NH}_{4}\right)_{2} \mathrm{SO}_{4} 3 ; \mathrm{KH}_{2} \mathrm{PO}_{4} 2 ; \mathrm{NaCl} 0.9$; the medium was supplemented with $1 \%$ and $2 \%$ of vegetable ( Sun flower oil) and crude oil individually used as an additional carbon source. The production medium was inoculated with $9 \% \mathrm{v} / \mathrm{v}$ of activated Candida. The cultivation was performed in $100 \mathrm{ml}$ Erlenmeyer flask at $30^{\circ} \mathrm{C}$ and $120 \mathrm{rpm}$ in a shaker incubator. 
The cell free supernatant was collected after centrifugation at $6000 \mathrm{rpm}$ for $30 \mathrm{~min}$. in $4^{\circ} \mathrm{C}$, and was analyzed for biosurfactant production [21].

\section{Optimization of biosurfactant production}

Two factors were chosen aiming to obtain higher productivity of biosurfactant carbon and nitrogen source which were employed at a concentration of $20 \mathrm{~g} / 1$ in MSM medium with $2 \%$ oil vegetable. The carbon source used were Glucose, Lactose, Fructose and Dextrin, for evaluation of the most appropriate nitrogen source for the production of biosurfactant Aspargin, L-Arginine, peptone and sodium nitrate were used, the media were autoclaved, inoculated with activated Candida broth at 30 ${ }^{\circ} \mathrm{C}$ and $120 \mathrm{rpm}$ in a shaker incubator for 7 days. The cell free supernatant was collected after centrifugation at $6000 \mathrm{rpm}$ for $30 \mathrm{~min}$. at $4{ }^{\circ} \mathrm{C}$, and were analyzed for biosurfactant production.

\section{$\underline{\text { 1- Oil displacement test }}$}

The oil displacement test was carried out by slowly dropping of $100 \mu 1$ of petroleum crude oil into the surface of $50 \mathrm{ml}$ of distillated water in a Petri dish ( $9 \mathrm{~cm}$ in diameter). $10 \mu 1$ of cell free metabolic liquid (crude biosurfactant) was then added to the surface of oil layer [22]. bio7 clear zone displacing the oil was measured in mm. distilled water was used as control.

\section{2-Emulsification index E24}

In this test $2 \mathrm{ml}$ of crude biosurfactant was added to $2 \mathrm{ml}$ of vegetable oil in a test tube and by vortexing at high speed for $2 \mathrm{~min}$. After $24 \mathrm{~h}$ the Emulsification index $\left(\mathrm{E}_{24}\right)$ was calculated by dividing the measure height of the emulsion layer on the total height of solution by 100 to expressing in percentage [23].

\section{3-Drop collapsing test}

This test is carried out by added two microliters of mineral oil into the Petri dish and equilibrate for one hr. at room temperature. five microliters of the culture supernatant was added to the surface of oil. The shape of drop on the oil surface was noted after one min. the culture supernatant that collapse the oil drop was indicated as positive $(+)$ to $(+++)$ corresponding partial to completed spreading on the oil surface while the culture supernatant which field to collapse the oil drop was indicated as negative (-). Distilled water was used as negative control. The procedure is discussed with some modification $[24,25]$. 


\section{4- Microcosm test for cleaning of oil contaminated vessels}

The test was conducted by using two beakers $(100) \mathrm{ml}$ to behave as oil tanks the beakers were filled with crude oil and left stagnant after $24 \mathrm{~h}$ they emptied, wall and bottoms were contaminated with residual oil. Some drops of culture supernatant softly introduced to one of the beakers the same drops of water was used as control. After $15 \mathrm{~min}$ the result were observed and reported as (+) to (+++) [26].

\section{$\underline{\text { Result and discussion }}$}

\section{Isolation and identification of Candida}

Although bacteria have been extensively studied for biosurfactant production, yeasts are also potential biosurfactant-producing microorganisms. Because of their unique structures, biosurfactants may have a greater range of properties that can be exploited commercially [27]. In the present study, Candida cruzi isolated from produced water of oil field was used for production of biosurfactant, Yeast can be preferred to bacteria as a source for biosurfactants because of its producing biosurfactant in higher concentration than bacteria and they do not present risk of inducing toxicity or pathogenic reaction [28]. The isolated colonies of Candida was appear after 7-10 days of incubation at $30^{\circ} \mathrm{C}$ on CSB medium, colonies was white round as shown in figure (1) these colonies identified as Candida cruzi after growing on Hicrome Candida Differential Agar where the colonies appear in purple color figure (2).

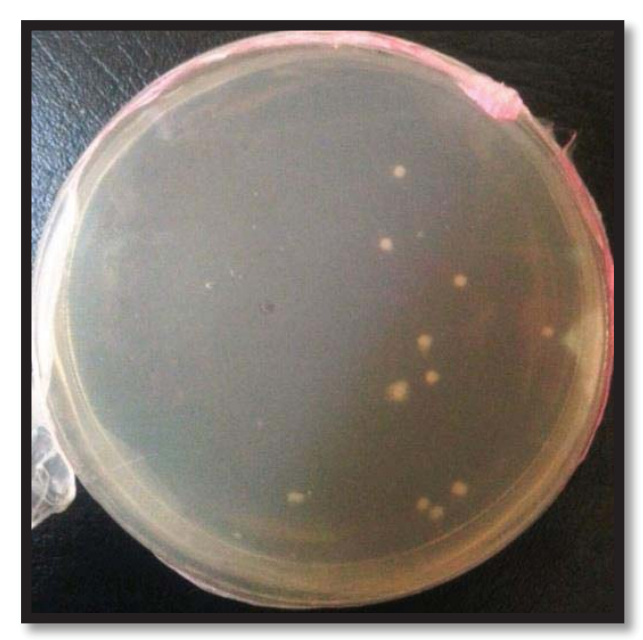

Fig. (1) Candida on CSB medium

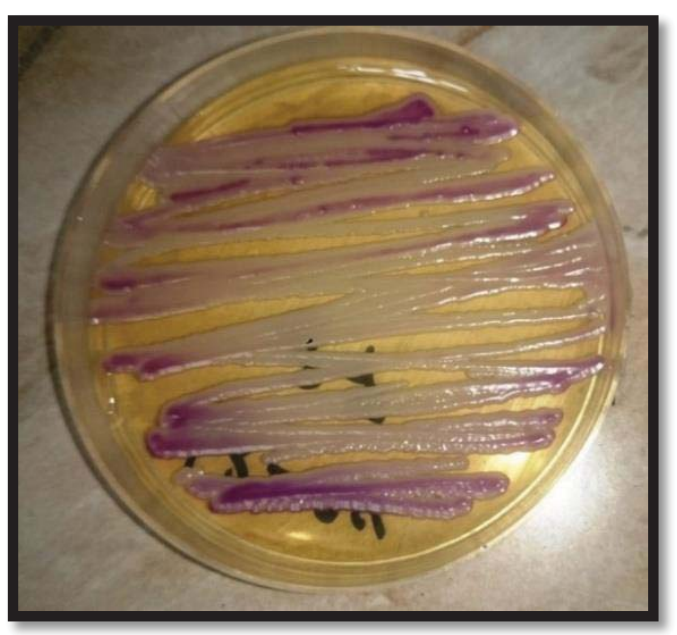

Fig. (2) Candida cruzi on Hicrom

Candida Differential Agar 


\section{1-Oil displacement test}

The yield of the crud biosurfactant produce by Candida cruzi isolate grown on sucrose as main carbon source and yeast extract as nitrogen source with $1 \%$ and $2 \%$ vegetable and crude oil was able to displaced the crude oil, the result of oil spreading showed that the largest zone $24 \mathrm{~mm}$ was observed with $2 \%$ vegetable oil as displayed in table (1) and figure (3).These result was compatible with previous studies of Sarubo [29] and Konishi [30] who used olive oil and canola oil for production of biosurfactant from Candida batistae CBS550 and C. lipolytica UCP0988 respectively. The used of vegetable oil as carbon source to produced biosurfactant seem to be an interesting alternative and low cost by the yeast [31, 32, 33, 34] found that incorporated in to aqueous solution the different stabilization properties of biosurfactant producing was when using the vegetable and mineral oils and the better stabilization properties when vegetable oil was used.

Table (1) Dispersant of the crude oil by biosurfactant extracted from candida.

\begin{tabular}{|c|c|c|c|}
\hline \multicolumn{3}{|c|}{ dispersant of oil / mm } \\
\hline \multicolumn{2}{|c|}{ Vegetable oil } & \multicolumn{2}{c|}{ Crude oil } \\
\hline $\mathbf{1 \%}$ & $\mathbf{2 \%}$ & $\mathbf{1 \%}$ & $\mathbf{2 \%}$ \\
\hline 18 & 24 & 10 & 11 \\
\hline
\end{tabular}

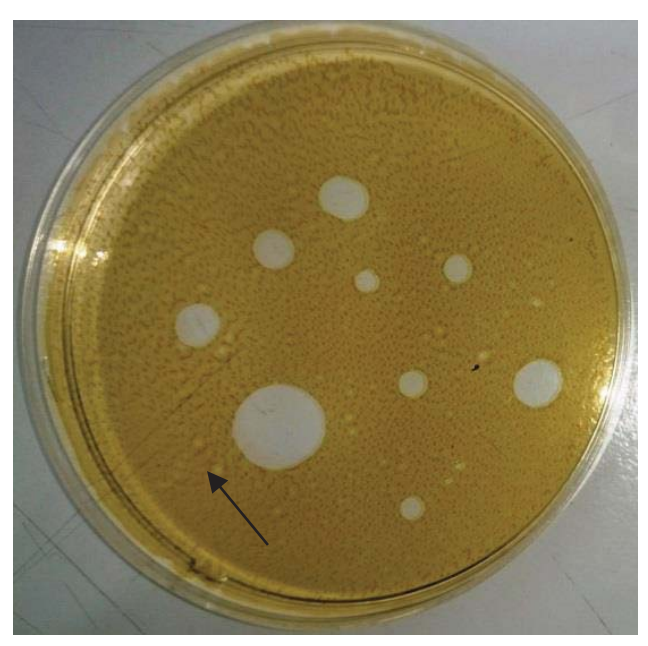

Fig. (3) Dispersion of crude oil by biosurfactant. 


\section{2-Emulsification activity E24}

The results of this test appear Candida cruzi ability to produce emulsifiers, the better emulsification activity E24 was about 25\% with 2\% crude oil table (2) and figure (4). This compatible with previous Studies by Cirigliano and Carman [35] who showed the produce of emulsifiers liposan by Candida lipolytica cultivated in hexadecane. also De Luna et al [36] showed the ability of Candida glabrata for production emulsifiers. The emulsifying property determines the strength of biosurfactant in retaining the emulsion of hydrocarbons or oil in water [23].

Table (2) Emulsification activity E24 of biosurfactant.

\begin{tabular}{|c|c|c|c|}
\hline \multicolumn{3}{|c|}{ Emulsification activity \% } \\
\hline \multicolumn{3}{|c|}{ Vegetable oil } & \multicolumn{2}{c|}{ Crude oil } \\
\hline $1 \%$ & $2 \%$ & $1 \%$ & $2 \%$ \\
\hline 18 & 18 & 15 & 25 \\
\hline
\end{tabular}

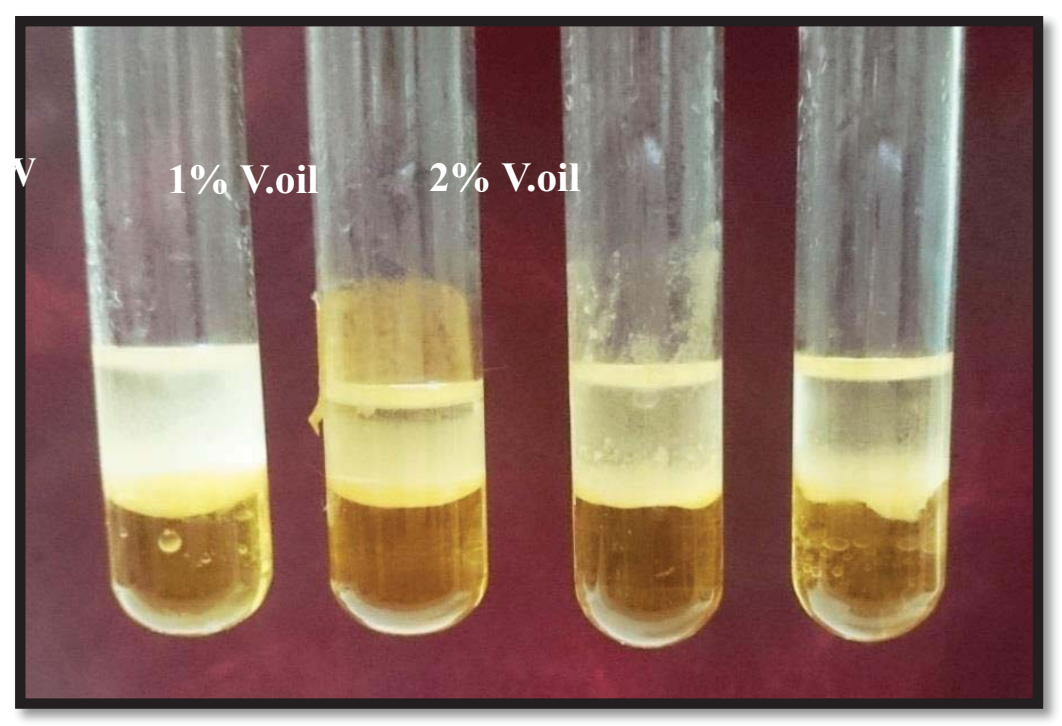

Fig. (4) Emulsification activity of biosurfactant.

\section{3-Oil drop collapse}

A rapid drop collapsing test was also employed to screen the Candida cruzi isolate for biosurfactant production, a drop of culture supernatant was flattened on oil surface leading to positive collapse reaction as (++) figure (5). This was agreed with previous studies [38,39]. 


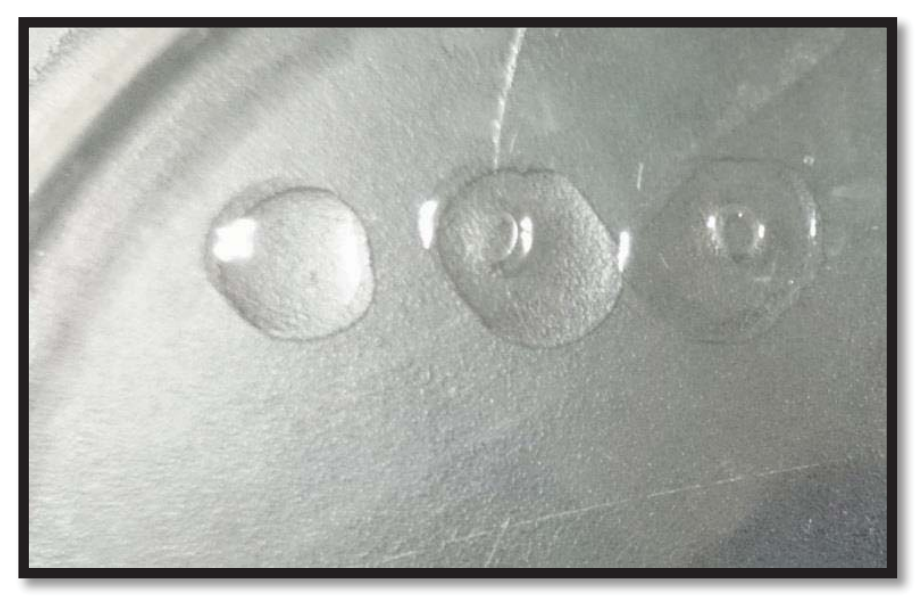

Fig. (5) Oil collapse of mineral oil drops.

\section{$\underline{4-M i c r o c o s m ~ t e s t ~ f o r ~ c l e a n i n g ~ o f ~ o i l ~ c o n t a m i n a t e d ~ v e s s e l s ~}$}

For cleaning of oil contaminated vessels the result showed that when the supernatant of the Candida was applied to the surface wall of beaker a few second after the application of biosurfactant small clear zone free from oil were developed in the wall $(++)$, when water was used, negligible result was observed. Heavy oil fractions and the waste that buildup on the walls and at the bottom of storage tanks are highly viscous and become solid deposits, solvents and manual cleaning are used to removal of this material which is expensive procedure, time consuming [40, 41]. Microbial biosurfactants form oil- water emulsion by decrease the viscosity of sludge and oil deposits which facilitates the pumping of waste [14]. The supernatant can be used for cleaning oil contaminated vessels and tanks, compared to chemical methods such clean process represent economically less hazardous this result agreed with Diab and Gamal Eldin [26] who evaluated the effect of P. aeruginosa SH 29 supernatant in cleaning of oil contaminated vessels and Chamanrokh et al. [42] who found that washing the oil contaminated vessels with 10 to $20 \mathrm{mg} / \mathrm{l}$ of biosurfactant solution readily form an oil- water emulsion.

\section{5-Optimization of biosurfactant production in different carbon sources}

The production of surfactant by the yeast in combination of a carbohydrate plus vegetal oil as a very interesting alternative has been demonstrated studied in previous works [32, 43, 44]. The medium optimization was perform by growing the selected Candida under study in different carbon and nitrogen source. The influence of the carbon source in biosurfactant production has been extensively studied in some microorganisms. Depending on the yeast strain different type of carbon source have been used [27].

The result of optimization of biosurfactant production in different carbon source were displayed in table (3), the high oil displacement was $9 \mathrm{~mm}$ with dextrin while the oil displacement was $73 \%$. The 
lactose and fructose was the best carbon source for surfactant producing which gave the effectiveness of emulsification activity E2492\% with low displacement oil 2-3 mm. Yarrowia lipolytica have high emulsification activity in the presence of glucose as a carbon source [45]. this was compatible with Sarubbo et al. [32]. Who observed the maximum biosurfactant production by Candida galbrata by using carbon source, [46]. shown that the sophorolipid yield from C. bombicola ATCC22214 increase with use carbon source also this was agreed with Khopade et al. [47]. who showed that carbon sources such as trehalose ,hexadecane and olive oil supported the growth of Nocardiopsis.

Amaral et al. [48] reported that the use of glucose as a carbon source was important for the production of Yansan by Yarrowia. Also Joice and Parthasarathi [49]. reported that isolate of Pseudomonas aeruginosa PBSCI was produce higher amount of biosurfactant in presence of glucose and glycerol.

Table (3) Effect of carbon sources affected on production of biosurfactant

\begin{tabular}{|l|c|c|c|}
\hline Carbon sources & Emulsification \% & Displacement mm & Oil recovery \\
\hline Glucose & $71.4 \%$ & $2 \mathrm{~mm}$ & ++ \\
\hline Lactose & $92.8 \%$ & $3 \mathrm{~mm}$ & +++ \\
\hline Fructose & $92.8 \%$ & $3 \mathrm{~mm}$ & + \\
\hline Dextrin & $73.3 \%$ & $9 \mathrm{~mm}$ & +++ \\
\hline
\end{tabular}

Proteins are essential for the growth of microbes, the fermentation process and production of enzymes so the nitrogen is important in biosurfactant production medium [50]. The effect of nitrogen sources affected on production of biosurfactant showed that L-Arginine was the best source of nitrogen for biosurfactant synthesis its gave the large zone of oil displacement $10 \mathrm{~mm}$ and the maximum emulsification activity was $73.3 \%$ table (4) figure (6) similar results were found with study of Santos et al. [51]. who showed that rhamnolipids are mainly produced by Pseudomonas species using various carbon sources such as vegetable oils and nitrogen source to achieve improve productivity.

The important factors in production of biosurfactant are carbon and nitrogen sources which have great influence their production cost [52]. The supernatant of Candida cruzi product was emulsifiers than the surfactant because emulsification power was better than oil displacement this was compatible with Alburquerque et al. [53] who showed that most of the biosurfactant produced by yeasts are better emulsifiers than biosurfactants, mainly because of the chemical structure Fontes et al. [54] reported that 
nitrogen source were important for cell growth and biosurfactant synthesis and the glucose and glycerol were the most efficient carbon source to produce biosurfactant by Yarrowia lipolytica .

Table (4) Effect of nitrogen sources affected on production of biosurfactant

\begin{tabular}{|l|c|c|c|}
\hline Nitrogen sources & Emulsification \% & Displacement mm & Oil recovery \\
\hline L-Arginine & $73.3 \%$ & $10 \mathrm{~mm}$ & $-\mathrm{e}$ \\
\hline Asparagine & $66.6 \%$ & $6 \mathrm{~mm}$ & +++ \\
\hline Sodium nitrate & $66.6 \%$ & $5 \mathrm{~mm}$ & ++ \\
\hline Peptone & $71.4 \%$ & $6 \mathrm{~mm}$ & + \\
\hline
\end{tabular}

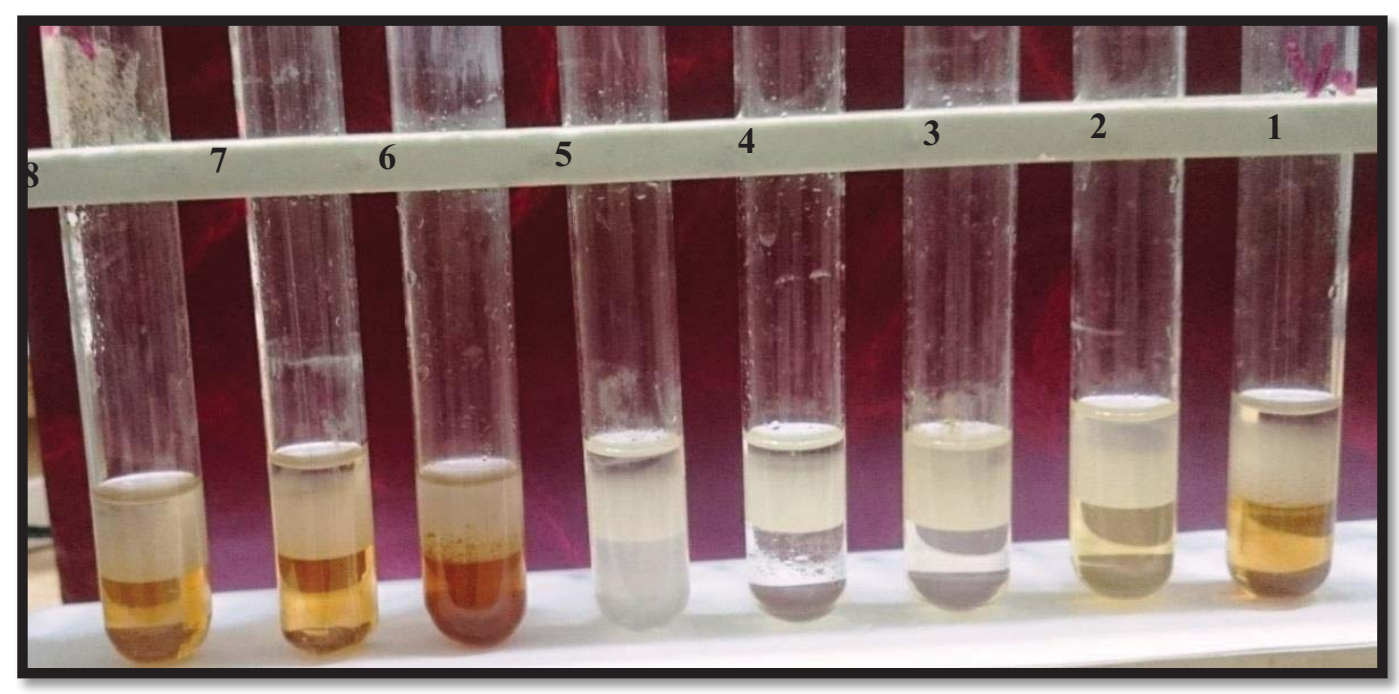

Fig. (6) Emulsification activity of optimization of biosurfactant with carbon and nitrogen source. (1) Glucose, (2) Lactose,(3) Fructose, (4) L- Arginine, (5)Aspargin, (6) Sodium nitrate, (7) Pepton and (8) Dextrine.

\section{Conclusion}

The biosurfactant produced by Candida cruzi showed biosurfactant production and emulsification activity. We have shown that this Candida can be induced to produced high emulsification activity when it's grown with lactose and fructose. It's reduced the cost of production of biosurfactant because the cell free broth containing surfactant can be used directly without purification test. So it's could be applied in enhanced oil recovery operations specially this Candida isolated from produced water of oil fields. 


\section{(JPR\&S)}

\section{$\underline{\text { References }}$}

1. Vijayakumar S. and Saravanan V. (2015).Biosurfactants-Types, Sources and Applications. Res. J. Microbiol. 10 (5): 181-192.

2. Muthusamy, K., S. Gopalakrishnan, T.K. Ravi and Sivachidambaram, P. 2008.Biosurfactants: properties, commercial production and application. Curr. Sci.94, 736-747.

3. Kapadia, S.G. and Yagnik, B.N. 2013.Current trend and potential formicrobial biosurfactants. Asian J. Exp. Biol. Sci. 4, 18.

4. Aparna, A.; Srinikethan, G.; Hedge, S. Effect of addition of biosurfactant produced by Pseudomonas ssp. on biodegradation of crude oil. In International Proceedings of Chemical, Biological \& Environmental Engineering. Proceedings of the 2nd International Proceedings of Chemical, Singapore, Singapore, 26-28 February 2011; Volume 6, pp. 71-75.

5. Ahimou, F., Jacques, P. and Deleu, M. (2000). Surfactin and iturin A effects on Bacillus subtilis surface hydrophobicity. Enz. Microb. Technol., 27: 749-754.

6. Casas, J.A., S.G. de Lara and F. Garcia-Ochoa, 1997. Optimization of a synthetic medium for Candida bombicola growth using factorial design of experiments. Enzyme Microb. Technol.,21: 221-229.

7. Sarubbo, L.A., C.B.B. Farias and G.M. Campos-Takaki, 2007. Co-Utilization of canola oil and glucose on the production of a surfactant by Candida lipolytica. Curr. Microbiol., 54: 68-73.

8. Daverey, A. and Pakshirajan, K. (2008). Production, characterization, and properties of sophorolipids from the yeast Candida bombicola using a low-cost fermentative medium. Appl. Biochem. Biotechnol.,158: 663-674.

9. H.S. El-Sheshtawy I. Aiad, M.E. Osman, A.A. Abo-ELnasr, A.S. Kobisy Production of biosurfactants by Bacillus $\mathrm{m}$ licheniformis and Candida albicans for application in microbial enhanced oil recovery. Egyptian Journal of Petroleum (2015).

10. Chandran, P. and N. Das, 2010. Biosurfactant production and diesel oil degradation by yeast species Trichosporonasahii isolated from petroleum hydrocarbon contaminated soil. Int. J. Eng. Sci. Technol., 2: 6942-6953.

11. Alejandro, C.S., H.S. Humberto and J.F. Maria, 2011. Production of glycolipids with antimicrobial activity by UstilagomaydisFBD12 in submerged culture. Afr. J. Microbiol. Res., 5: $2512-25$. 
12. Banat I. M. Biosurfactants production and possible uses in microbial enhanced oil recovery and oil pollution remediation: A review, Bioresource Technol, 1995; 51: 112.

13. Yin, H. and J. Qiang, 2008. Characteristics of biosurfactant produced by Pseudomonas aeruginosa S6 isolated from oil containing wastewater. Process Biochemistry, 11: 367-373.

14. Silva, E.J.; Rocha e Silva, N.M.P.; Rufino, R.D.; Luna, J.M.; Silva, R.O.; Sarubbo, L.A. Characterization of a biosurfactant produced by Pseudomonas cepaciaCCT6659 in the presence of industrial wastes and its application in the biodegradation of hydrophobic compounds in soil. Colloids Surf. B Biointerfaces 2014, 117, 36-41.

15. W. Demin, C. Jiecheng, L. Qun, L. Lizhong, Z. Changjiu, H. Jichun, An alkaline Biosurfactant Polymer Flooding Pilots inDaqing Oil Field, Malaysia Conference, 1999, SPE, 57304.

16. Banat IM, Makkar RS, Cameotra SS. Potential commercial applications of microbial surfactants. Appl. Microbiol. Biotechnol. 2000 May;53(5):495-508.

17. Sobrinho, H.B.S.; Luna, J.M.; Rufino, R.D.; Porto, A.L.F.; Sarubbo, L.A. Assessment of toxicityof a biosurfactant from Candida sphaerica UCP 0995 cultivated with industrial residues in a bioreactor. Electron. J. Biotechnol. 2013, 16, doi:10.2225/vol16-issue4-fulltext-4.

18. Muthusamy K., Gopalakrishnan S., Ravi T.k., Sivachidambaram P., 2008, Biosurfactants: properties, commercial production and application, Current Science. 94, 736-746.

19. Gevertz, D.; Telang, A. J.; Voordouw, G.; and Jenneman, G. E. (2000). Isolation and characterization of strains CVO and FWKO B, two novel nitrate-reducing, sulfideoxidizing bacteria isolated from oil field brine, Appl. Environ. Microbiol., 66: 2491 -2501.

20. Muneer Ahmed Qazi, Mishal Subhan, Nighat Fatima, Muhammad Ishtiaq Ali, and Safia Ahmed Role of Biosurfactant Produced By Fusarium sp. BS-8 in Enhanced Oil Recovery (EOR) Through Sand Pack Column. International Journal of Bioscience, Biochemistry and Bioinformatics, Vol. 3, No. 6, November 2013.

21. Youssef, N.H., K.E. Duncan, D.P. Nagle, K.N. Savage and R.M. Knapp et al., 2004. Comparison of methods to detect biosurfactant production by diverse microorganisms. J. Microbiol. Methods, 56: 339-347. DOI: 10.1016/j.mimet.2003.11.001.

22. Cooper, D. and Goldenberg, B. (1987): Surface active agents from two Bacillus species. Appl. Environ. Microbiol., 53: 224-229.

23. Deepika L, Kannabiran K (2010) Biosurfactant and heavy metal resistance activity of Streptomyces spp. isolated from saltpan soil. Br. J. Pharmacol. Toxicol. 1(1):33-39. 
24. Yousaf S, Andria V, Reichenauer TG, Smalla K, Sessitsch A (2010) Phylogenetic and functional diversity of alkane degrading bacteria associated with Italian ryegrass (Loliummultiflorum) and Birdsfoot trefoil (Lotus corniculatus) in apetroleum oil-contaminated environment. J Hazard Mater 184:523-532.

25. Ali Diab and Shereen Gamal El Din Application of the biosurfactants produced by Bacillus spp. (SH 20 and SH 26) and Pseudomonas aeruginosa SH 29 isolated from the rhizosphere soil of an Egyptian salt marsh plant for the cleaning of oil contaminated vessels and enhancing the biodegradation of oily sludge ,African Journal of Environmental Science and Technology ,Vol. 7(7), pp. 671-679, July 2013.

26. Claudia Isabel Sáenz-Marta, María de Lourdes Ballinas-Casarrubias,Blanca E. Rivera-Chavira and Guadalupe Virginia Nevárez-Moorillón Biosurfactants as Useful Tools in Bioremediation Advances in Bioremediation of Wastewater and Polluted Soil. http://dx.doi.org/10.5772/60751 2015.

27. Rocha L., De Aguair R., Martins R., Ferreia R., Silveira S., Tédde S., Maciel V. Isolation and characterization of phenol-degrading yeast from an oil refinery waste water in Brazil. Mycopathologia. 2007;164, 183-188.

28. L. Sarubbo, C. Farias, and G. M. Campos-Takaki, "Co-utilization ofcanola oil and glucose on the production of a surfactant by Candidalipolytica," Curr. Microbiol, vol. 54, pp. 68-73, 2007.

29. M. Konishi, T. Fukuoka, T. Morita, T. Imura, and D. Kitamoto,"Production of new types of sophorolipids by Candida batistae,” J.Oleo Sci., vol. 57, pp. 359-369, 2008.

30. Davila, A.M.; Marchal, R. and Vandecastele, J.P.(1992), Kinetics and balance of a fermentation free from product inhibition: sophorose lipid production by Candida bombicola. Applied Microbiology and Biotechnology. 38 6-11.

31. Sarubbo, L.A.; Luna, J.M.; and Campos-Takaki, G.M.(2006), Production and stability studies of the bioemulsifier obtained from a new strain of Candida glabrata UCP 1002. Eletronic Journal of Biotechnology.

32. M. Abouseoud, R. Maachi, A. Amrane, S. Boudergua, A. Nabi, Evaluation of different carbon and nitrogen sources in production of biosurfactant by Pseudomonas fluorescens, Desalination 223 (2008) 143-151.

33. Silva L.A., Monte A.R. Evaluation of emulsifier stability of biosurfactant produced by Saccharomyces lipolyticaCCT-0913. Brazilian Archives of Biology and Technology.2009; 52(2), 285-290. 
34. Cirigliano MC, Carman GM. Isolation of a bioemulsifier from Candida lipolytica. Appl. Environ. Microbiol, 1984; 48(4):747-50.

35. Juliana Moura de Luna1, Leonie Sarubbo2,3 and Galba Maria de Campos Takaki 2,3 A New Biosurfactant Produced by Candida glabrataUCP1002: Characteristics of Stability and Application in OilRecovery Vol.52, n.4: pp.785-793, July-August 2009. BRAZILIAN ARCHIVES OFBIOLOGY AND TECHNOLOGY.

36. Jazeh G. Forghani M., F. and Deog-Hwan O. Biosurfactan Production by Bacillus sp. Isolated from Petroleum Contaminated Soils of Sirri Island. American J. Appl. Sci., 9 (1): 1-6, 2012.

37. Mrinalini J Singh* and Padmavathy Sedhuraman Biosurfactant, polythene, plastic, and diesel biodegradation activity of endophytic Nocardiopsis sp. mrinalini9 isolated from Hibiscus rosasinensis leaves Bioresources and Bioprocessing (2015) 2:2.

38. Perfumo, A.; Rancich, I.; Banat, I.M. Possibilities and challenges for biosurfactants use in petroleum industry. Adv. Exp. Med. Biol. 2010, 672, 135-145.

39. Matsui, T.; Namihira, T.; Mitsuta, T.; Saeki, H. Removal of oil tank bottom sludge by novel biosurfactant, JE1058BS. J. Jpn. Pet. Inst. 2012, 55, 138-141.

40. Chamanrokh P, Mazaheri Assadi M, Amoabediny Gh. Rashidi H (2010). Cleaning oilcontaminated vessel by emulsan producers (autochthonous bacteria). Iran J. Environ. Health 7(3): 209-222.

41. Davila, A.M.; Marchal, R. and Vandecastele, J.P.(1992), Kinetics and balance of a fermentation free from product inhibition: sophorose lipid productionby Candida bombicola. Applied Microbiology and Biotechnology. 38 6-11.

42. Garcia-Ochoa, F. and Casas, J.A. (1999), Unstructured kinetic model for sophorolipid production by Candida bombicola. Enzyme and Microbial Technology. 25, 613-621.

43. P.F.F. Amarala, J.M. da Silva b, M. Lehockyb, A.M.V. Barros-Timmons b, M.A.Z. Coelho a, I.M. Marrucho, J.A.P. Coutinhob, ${ }^{*}$ Production and characterization of a bioemulsifier from Yarrowia lipolytica Process Biochemistry 41 (2006) 1894-1898.

44. Cavalero DA, Cooper DG, 2003. The effect of medium composition on the structure and physical state of sophorolipids produced by Candida bombicola ATCC 22214. Journal of Biotechnology, 103: 31-41. 
45. A. Khopade, R. Biao, X. Liu, K. Mahadik, L. Zhang, C. Kokare Production and stability studies of the biosurfactant isolated from marineNocardiopsis sp. B4 , Desalination 285 (2012) 198204

46. Amaral P.F., Coelho Z. M., Marrucho I.M., Coutinho A.P.J. Biosurfactants from yeast:characteristics, production and application. Advances in Experimental Medicine andBiology 2010;672, 236-249.

47. P.Anna Joice1 and R. Parthasarathi. Optimization of biosurfactant production from Pseudomonas aeruginosa PBSC1( 2014) Int.J.Curr.Microbiol.App.Sci. (2014) 3(9) 140-151.

48. Saharan BS, Sahu RK, Sharma D. 2011. Review on Biosurfactants: Fermentation, Current Developments and Perspectives. Genet. Eng. Biotechnol. J. GEBJ-29:1-14.

49. Santos, A. S. Sampaio APW, Vasquez GS, Santa Anna LM, Pereira Jr N, Freire DMG.Evaluation of different carbon and nitrogen sources in production of rhamnolipidsby a strain of Pseudomonas aeruginosa. Applied Biochemistry and Biotechnology-Part A Enzyme Engineering and Biotechnology. (2002).

50. Henkel, M, Müller, M. M, Kügler, J. H, Lovaglio, R. B, Contiero, J, Syldatk, C, et al.

51. Rhamnolipids as biosurfactants from renewable resources: Concepts for next-generation rhamnolipid production. Process Biochemistry. (2012). , 47(8), 1207-19.

52. Alburquerque C.D.C., Filetti A.M.F., Campos-Takaki G.M. Optimizing the medium components in bioemulsifiers production by Candida lipolyticawith response surface method. Canadian Journal of Microbiology. 2006;52, 575-583.

53. Fontes G.C., Ramos N.M., Amaral P.F.F., Coelho M.A., 2012, Renewable resources for biosurfactant production by Yarrowia lipolytica, Brazilian Journal of Chemical Engineering, 29, 483-493. 